\title{
Valve-sparing aortic root replacement can be done safely and effectively in acute type $\mathrm{A}$ aortic dissection
}

Zara Khachatryan, MD, Johanna Herajärvi, MD, $\mathrm{PhD}$, Sergey Leontyev, $\mathrm{MD}, \mathrm{PhD}$, and

Michael A. Borger, MD, PhD

Video clip is available online.

Feature Editor's Introduction-Despite a multitude of advancements in surgical technique and perioperative care, repair of an acute type A aortic dissection (ATAAD) is still associated with disappointingly high mortality and morbidity. Although operative mortality from highervolume centers and surgeons may be $<10 \%$, large datasets such as The International Registry of Aortic Dissection and the German Registry for Acute Aortic Dissection Type A are more representative of real-world outcomes with 30-day and in-hospital mortality still approaching 20\%. For those fortunate survivors, late aortic root dilatation and aortic valve insufficiency, in addition to downstream aortic dilatation, leads to the need for additional high-risk operations such as aortic root replacement and thoracoabdominal aneurysm repair. Would a more aggressive approach during the index ATAAD operation be justified if it could reduce the need for these high-risk late reinterventions?

The risks associated with late reoperations on the aortic root and downstream aorta have led to more widespread utilization of innovative technology and complex procedures during ATAAD repair. Devices such as the frozen elephant trunk optimize aortic remodeling in the descending aorta and may ultimately reduce the need for highrisk open or endovascular thoracoabdominal repair. However, the spinal cord dysfunction associated with this well-intended technique has encouraged a more tempered application of the frozen elephant trunk device. Another innovative surgical technique, valve-sparing aortic root replacement, is being performed in greater numbers in patients with ATAAD in the hopes of eliminating late aortic

From the University Clinic of Cardiac Surgery, Leipzig Heart Centre, Leipzig, Germany.

Drs Khachatryan and Herajärvi contributed equally to this article.

Received for publication Dec 14, 2020; revisions received Feb 10, 2021; accepted for publication Feb 12, 2021; available ahead of print April 3, 2021.

Address for reprints: Michael A. Borger, MD, PhD, University Clinic of Cardiac Surgery, Leipzig Heart Centre, Struempellstrasse 39, 04289 Leipzig, Germany

(E-mail: michael.borger@helios-gesundheit.de).

J Thorac Cardiovasc Surg 2022;164:814-9

$0022-5223 / \$ 36.00$

Copyright (c) 2021 by The American Association for Thoracic Surgery

https://doi.org/10.1016/j.jtcvs.2021.02.101

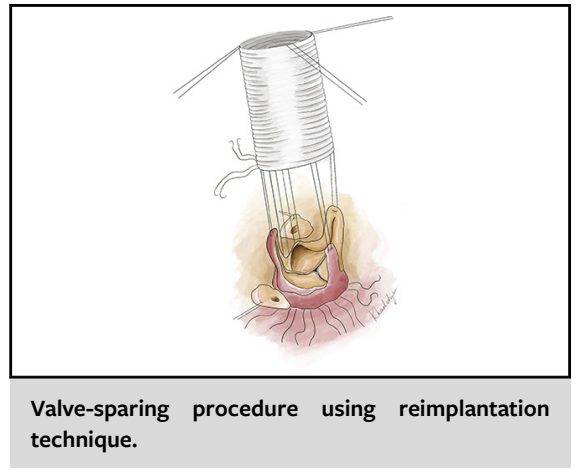

CENTRAL MESSAGE

The David procedure, when performed by experienced surgeons

in appropriately selected patients, is a safe and effective treatment option in patients with acute type $A$ aortic dissection.

See Commentary on page $\mathbf{8 2 0}$.

root dilatation. In the hands of experienced surgeons such as those in The Leipzig Heart Centre, valve-sparing aortic root replacement has become the procedure of choice for root replacement in properly selected patients. Longerterm follow-up will be necessary to document the durability of this procedure with respect to aortic valve function.

\section{Leonard N. Girardi, MD}

Acute type A aortic dissection (ATAAD) remains among the most challenging medical emergencies, being associated with increased mortality even when recognized early and treated appropriately. Unlike type B aortic dissection, ATAAD remains a prerogative of open surgery, mainly due to complexity of the disease leading to severe aortic valve dysfunction; coronary, cerebral, and visceral malperfusion; and a dramatically increased risk of aortic rupture. ${ }^{1,2}$

The aim of surgical treatment of ATAAD should be, first and foremost, to save the patient's life in an acute setting. However, providing a stable long-term result and reducing the risk of late complications and reinterventions should remain important secondary considerations, particularly in younger patients. We firmly believe that aortic valve reimplantation (ie, David procedure) should be considered in 
many ATAAD patients because of its long-term benefits, provided that it can be performed safely and effectively. We therefore review current techniques, indications, and results of the David operation in patients presenting with ATAAD.

\section{INDICATIONS FOR DAVID PROCEDURE AND OTHER AORTIC ROOT INTERVENTIONS}

Aortic insufficiency (AI) in ATAAD is caused in the vast majority of patients by the dissection of tissue supporting 1 or more commissures, whereas the aortic valve cusps remain structurally intact. In this setting, several surgical approaches are possible. In cases when only 1 of the aortic sinuses is dissected, surgical decompression of the false lumen followed by resuspension of the commissure(s) is possible. Also, the dissected tissue may be reinforced using either polytetrafluoroethylene (eg, sandwich technique) or/ and by means of tissue adhesive. ${ }^{3}$ Alternatively, a one-third or mini Yacoub procedure with replacement of the ascending aorta and 1 of the sinuses, usually the noncoronary sinus, with a tongue of graft material can be performed. The above-mentioned methods are less complex than aortic root replacement techniques, and therefore do not require prolonged cardiopulmonary bypass (CPB) and myocardial ischemia times.

When the aortic valve cusps are deteriorated or calcified, full aortic root replacement (ie, Bentall procedure) using either a valved (ie, mechanical or biological) conduit or a xenograft root conduit should be performed. In all other cases of ATAAD with AI (ie, in patients with pliable aortic valve cusps), valve-sparing aortic root replacement can be performed. The 2 principal types of valve-sparing procedures are the Yacoub (ie, aortic root remodeling) and the David (ie, aortic valve reimplantation) procedures, both introduced in the early $1990 \mathrm{~s} .{ }^{4,5}$ Long-term complications of biological or mechanical valve replacement can be mostly avoided with these procedures, but they involve longer CPB and ischemic times than a Bentall procedure. As such, valve-sparing procedures are predominantly indicated in younger patients (ie, younger than age 65 years) without significant medical or ATAAD-related comorbidities (eg, coronary artery disease, mesenteric malperfusion, or preoperative cardiopulmonary resuscitation). In addition, the surgeon should be experienced in performing these technically challenging procedures in nonacute settings.

\section{MODIFICATIONS AND SIZING}

A great number of modifications of valve-sparing procedures in general, and David technique in particular, have been developed during the last decades (Figure 1). A well-known classification system by Miller ${ }^{6}$ described the following valve preservation techniques. David I is the original procedure introduced by Tirone David, consisting of reimplantation of the aortic valve into a straight tube graft with its fixation to the ventriculo-aortic junction, with lifting and fixation of the valve commissures and reimplantation of the coronary arteries. ${ }^{4}$ David II is in fact the Yacoub remodeling procedure, based on the excision of the Valsalva sinuses and suturing of the tongued ascending aortic graft to the remaining aortic sinus tissue aortic annulus and reimplantation of the coronary arteries. The Yacoub technique is believed to provide better hemodynamic parameters and allow a more physiological cusp motion. ${ }^{7}$ However, the lack of annulus stabilization can lead to postoperative annular dilatation and recurrent AI, particularly in patients with connective tissue disorder. ${ }^{8}$ To solve this problem, another variation of the Yacoub procedure (ie, David III) was developed, consisting of a combination of remodeling with an external annuloplasty. ${ }^{9}$ The David IV and David V techniques are based on the use of larger tubular graft sizes for the reimplantation (ie, 2-4 $\mathrm{mm}$ and 4-8 $\mathrm{mm}$ larger, respectively), where the grafts are narrowed down either at the top margin of the aortic root only (David IV), or both at the top and the bottom margins of the aortic root (David V).

Other alternative approaches, also aiming to create neosinuses, are based on using 2 grafts of different sizes (Stanford technique ${ }^{10}$ ), or reimplantation of the valve into a

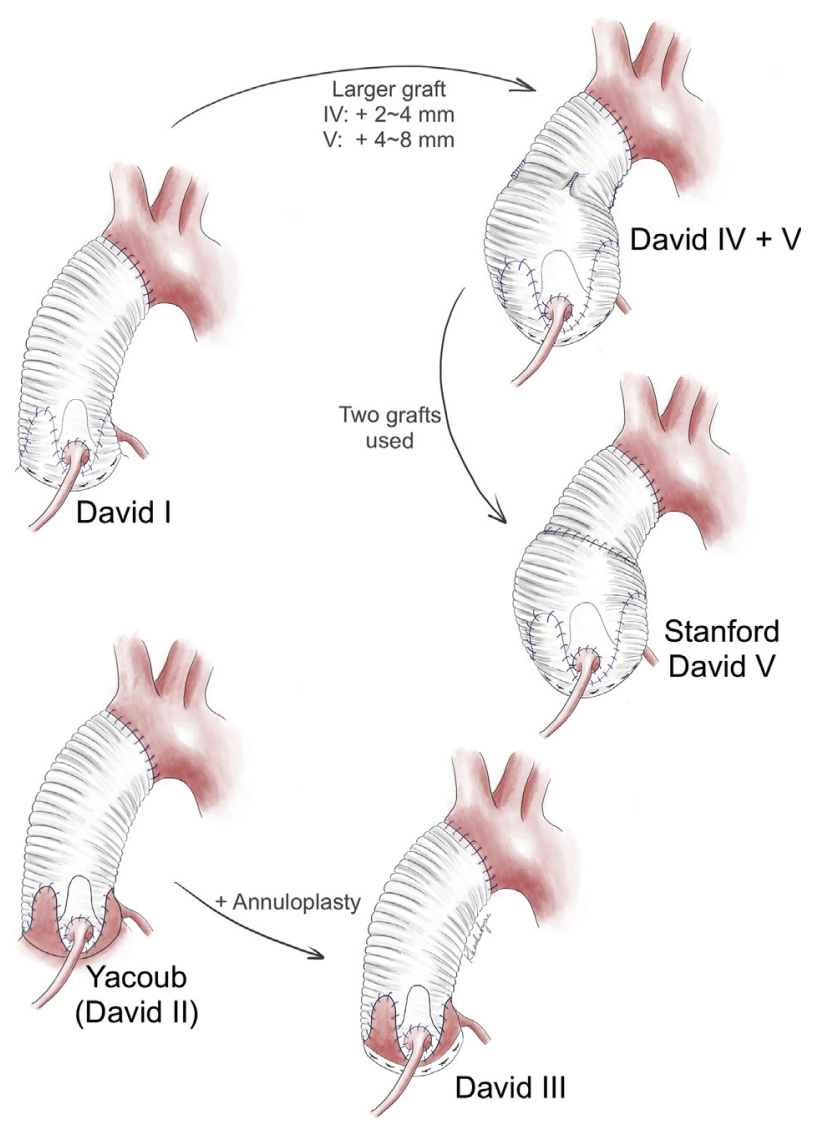

FIGURE 1. David and Yacoub procedures and their modifications. 
premanufactured graft with artificially created Valsalva sinuses. However, some of these grafts (eg, Gelweave Valsalva; Vascutek Ltd, Inchinnan, United Kingdom, and Cardioroot; Getinge Group, Getinge, Sweden) have a spherically shaped neosinuses that could theoretically cause displacement of the commissures and, as a result, valve insufficiency. ${ }^{11}$ As an alternative, a Uni-Graft W Sinus (B. Braun, Melsungen, Germany) was developed to mimic the anatomy of the aortic root, ${ }^{12}$ but is no longer available. At our center, we most commonly use the David I or David $\mathrm{V}$ techniques, using a standard straight tube graft.

An important aspect of any type of the David procedure is graft sizing. The original method is based on the FeindelDavid formula, where the diameter of the aortic annulus is equal to two-thirds of the height of the cusps ${ }^{4}$ :

$$
\begin{aligned}
\text { Graft size }= & ((\text { average cusp height } \times 2) \\
& \times(2 / 3)+(\text { aortic wall thickness })) .
\end{aligned}
$$

Later, David himself described using grafts that were approximately twice the mean heights of the valve cusps for the David V procedure. ${ }^{13}$ De Kerchove and colleagues ${ }^{14}$ introduced a technique whereby the aortic valve annular diameter is chosen based on the height of the interleaflet triangle at the left/noncoronary commissure. Gleason ${ }^{15}$ suggested creating neosinuses using another formula based on the cusps' height: (cusps' height $\times 2)+1 \sim 2 \mathrm{~mm}$. De Paulis and colleagues ${ }^{16}$ suggested measuring the aortic annulus using a Hegar dilator and adding $5 \mathrm{~mm}$ to it.

The majority of currently available complex formulas for graft sizing are based on relative dimensions of the normal aortic root. ${ }^{17}$ However, some of the patients requiring the David procedure no longer have normal root anatomy, particularly patients with large aneurysms or bicuspid aortic valves. For this reason, choosing the size of the graft based solely on fixed normal aortic valve dimensions (eg, annular diameter), may be misleading.

The main aim of sizing is to achieve an appropriate aortic cusp coaptation zone and length, while at the same time not inducing prolapse. In the Leipzig Heart Centre, we therefore perform sizing of the graft by vertically lifting the 3 aortic valve commissures following their extensive mobilization, and positioning the commissures in a circular pattern to achieve appropriate cusp coaptation (Figure 2). The diameter of this imaginary sinotubular junction circle (usually $26-28 \mathrm{~mm}$, occasionally $30 \mathrm{~mm}$ ) is chosen as the graft size for a David I procedure, or 4 to $8 \mathrm{~mm}$ is added to this value for a David $\mathrm{V}$ procedure.

It should be stressed that extensive mobilization of the entire aortic annulus, so that the aortic valve can be completely pulled out of the left ventricular outflow tract without tension on any part of the annulus (see Video 1), is a key element of any successful David operation. In patients with ATAAD, the mobilization of the proximal

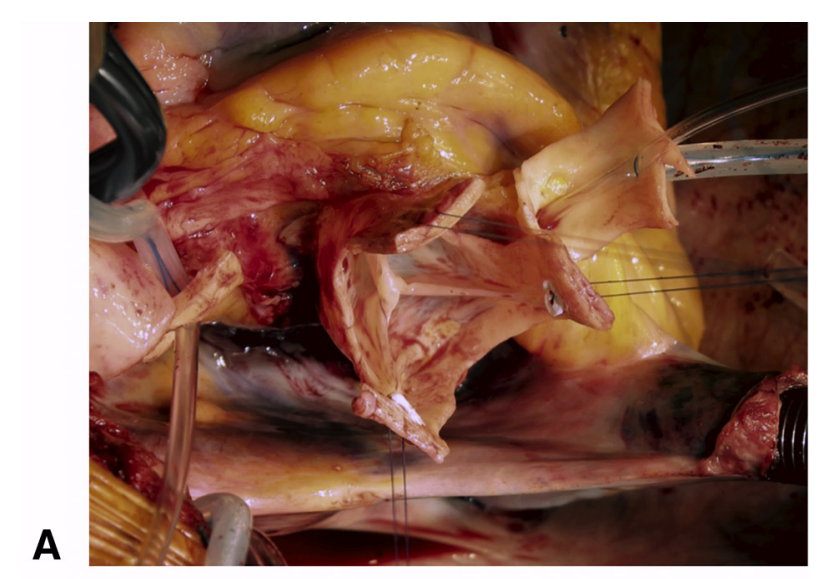

B

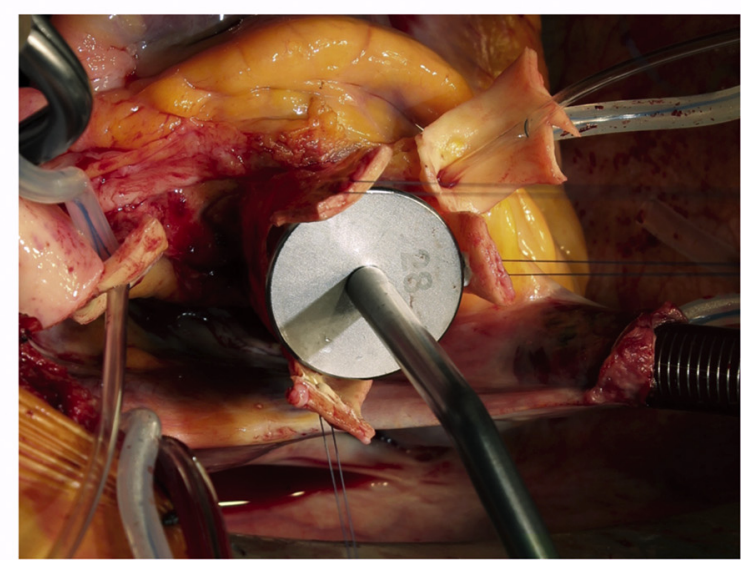

FIGURE 2. A, Sizing of the sinotubular junction diameter that will result in optimal aortic valve cusp coaptation. B, The measured diameter of the imagined circle at the level of the sinotubular junction (in this case, $28 \mathrm{~mm}$ ) corresponds to the diameter of the graft in David I operation, or 4 to $8 \mathrm{~mm}$ is added to this value for a David V procedure.

portion of the aortic root is usually complicated by the dissection of the aortic wall layers, as well as by surrounding hematoma. It is critical to preserve the adventitial layer of the aortic root during this portion of the procedure (see Video 2), which is then secured along with the detached intima media to the inner surface of the aortic graft with a running polypropylene 4-0 suture (see Video 3).

\section{REVIEW OF THE LITERATURE}

Despite growing interest, implementation of the David procedure in an acute aortic dissection setting is limited. According to the German Registry for Acute Aortic Dissection Type A, only $6.2 \%$ of ATAAD patients underwent valve preservation using the reimplantation technique. ${ }^{18}$ This could be explained by the fact that the David procedure is technically demanding and is associated with prolonged myocardial ischemia and CPB times. For this reason, it may be unsuitable in hemodynamically unstable patients, ATAAD complicated by malperfusion, elderly patients, or those with severe comorbidities. Another limitation of this 


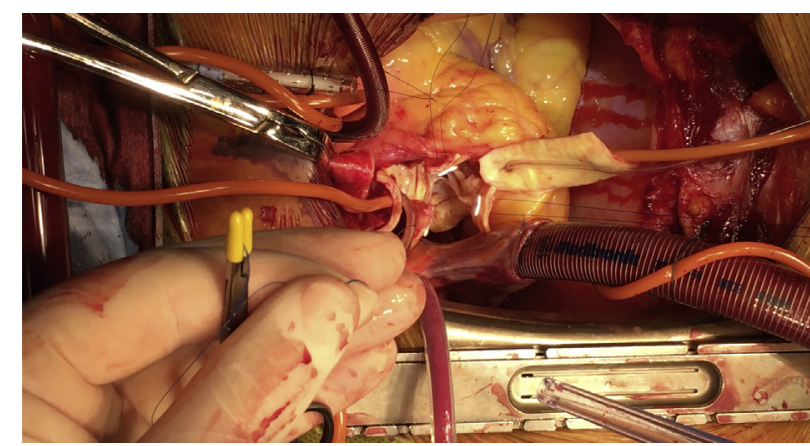

VIDEO 1. Extensive mobilization of the entire aortic valve and annulus is required in order to achieve good cusp coaptation following implantation in the aortic prosthetic graft, and can be confirmed by pulling up on the commissures without visible retraction of any element of the valve apparatus. Sizing of the aortic graft can now be performed. Video available at: https://www.jtcvs.org/article/S0022-5223(21)00585-7/fulltext.

technique is that it requires extensive dissection of the tissues surrounding the aortic root, which in the presence of massive dissection, hematomas, and coagulopathy, may be challenging even for experienced surgeons.

On the other hand, the David procedure offers some valuable long-term advantages over remodeling and valved conduit root replacement. In a small study with 30 ATAAD patients and 2-year mean follow-up, Ley and colleagues ${ }^{19}$ reported freedom from reoperation due to aortic valve structural failure as 38\% after Yacoub and 100\% after David procedure. We retrospectively compared the Yacoub (onethird Yacoub in most of the cases), David and Bentall procedures in ATAAD, but found no statistically significant difference in freedom from aortic valve reintervention rates. ${ }^{20}$ It should be noted that there were no patients with Marfan syndrome who underwent the Yacoub procedure in our study, emphasizing the importance of appropriate patient selection.

In a systematic review, Mosbahi and colleagues ${ }^{21}$ analyzed 27 studies on this subject with a total of 3058 ATAAD patients (1991-2016). They showed that the David

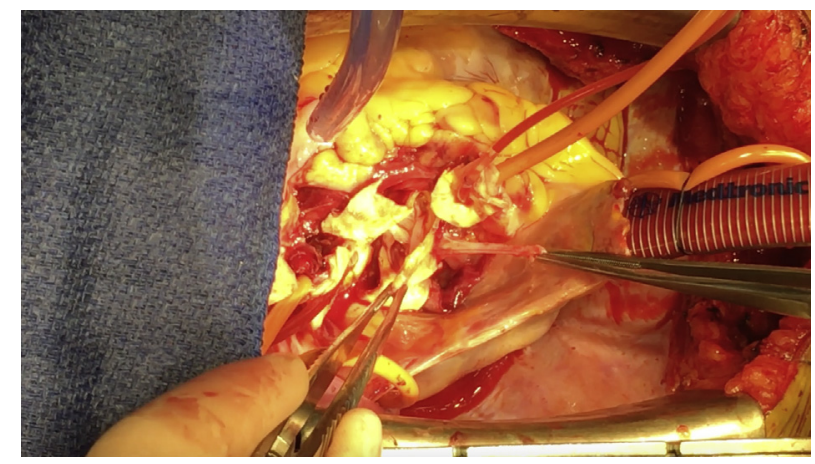

VIDEO 2. Preservation of the dissected adventitial layer is critical in patients with dissection of the proximal aortic root. Video available at: https:// www.jtcvs.org/article/S0022-5223(21)00585-7/fulltext.

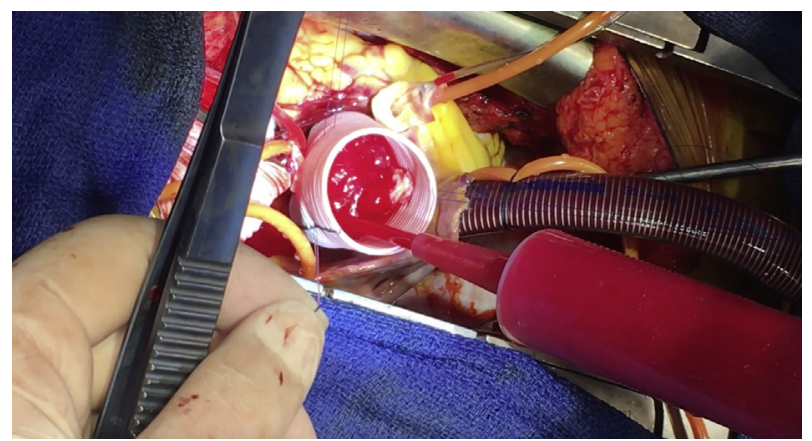

VIDEO 3. The adventitial and intimal/medial layers of the aortic root are reimplanted together within the aortic graft, and the valve is tested for competency. Video available at: https://www.jtcvs.org/article/S0022-5223(21) 00585-7/fulltext.

procedure was superior to the Bentall technique in terms of in-hospital mortality $(2 \%$ vs $8 \%)$ and midterm survival (99\% vs $81 \%)$. The rate of early postoperative stroke was $2.7 \%$ after David and $5.1 \%$ after the Bentall procedure, and thromboembolic events during follow-up were also significantly lower in David patients (0.5\% vs $4.9 \%)$. Some of these differences are undoubtedly due to selection bias, but the David operation may be particularly helpful in avoiding known long-term prosthetic valve complications such as thromboembolism, structural valve deterioration, and endocarditis. ${ }^{22}$ It also diminishes the negative effect of long-term anticoagulation therapy on false lumen thrombosis in patients with extensive aortic dissection.

The relatively limited published evidence of the David procedure in ATAAD may be explained by the fact that very few aortic centers routinely perform this technique in this critically ill group of patients. Nonetheless, it has been shown that David procedure does not compromise early and midterm survival in ATAAD in experienced centers. $^{20,23,24}$

\section{Leipzig Heart Centre Results}

During the period from 1995 to 2018,114 patients underwent an aortic valve-sparing procedure for ATAAD at our center. A total of 59 Yacoub procedures were performed, of which 52 were a one-third or mini Yacoub. Fifty-five patients underwent the David procedure: 34 (62\%) David I and $21(38 \%)$ David V repairs. Perioperative data and early outcomes are presented in Table 1. Compared with our previously published series, including all types of root interventions for ATAAD, there were fewer critically ill patients in the current David procedure analysis $(16 \%$ vs $33 \%$ in Leontyev and colleagues ${ }^{2}$ ). Malperfusion syndrome was also less frequent, being present in $29 \%$ of cases versus $37 \%$ in the study by Leontyev and colleagues. ${ }^{2}$ With regard to operative complexity, the David procedure was performed frequently in cases of extensive aortic arch 
TABLE 1. Perioperative data and early postoperative outcomes after David procedure in acute type A dissection $(n=55)$

\begin{tabular}{|c|c|}
\hline Variable & Result \\
\hline \multicolumn{2}{|l|}{ Preoperative characteristics } \\
\hline Age (y) & $51.4 \pm 12.1$ \\
\hline Male & $42(76)$ \\
\hline Connective tissue disorders & $5(9)$ \\
\hline Bicuspid aortic valve & $1(2)$ \\
\hline Cardiopulmonary resuscitation & $1(2)$ \\
\hline Inotropic support & $5(9)$ \\
\hline Ventilation & $6(11)$ \\
\hline Pericardial tamponade & $11(20)$ \\
\hline Preoperative critical state & $9(16)$ \\
\hline Malperfusion & $16(29)$ \\
\hline Cerebral & $11(20)$ \\
\hline Coronary & $4(7)$ \\
\hline Visceral & $3(5)$ \\
\hline Extremity & $6(11)$ \\
\hline \multicolumn{2}{|l|}{ David procedure type } \\
\hline David I & $34(62)$ \\
\hline David V & $21(38)$ \\
\hline \multicolumn{2}{|l|}{ Concomitant procedures } \\
\hline GFR glue around the coronary buttons & $5(9)$ \\
\hline Coronary artery patch plasty or bypass & $9(16)$ \\
\hline Mitral valve replacement & $1(2)$ \\
\hline Extent of distal aortic resection & \\
\hline Isolated ascending aortic replacement & $4(7)$ \\
\hline Hemiarch & $34(62)$ \\
\hline Total arch & $5(9)$ \\
\hline Elephant trunk & $12(22)$ \\
\hline \multicolumn{2}{|l|}{ Operative data } \\
\hline Cardiopulmonary bypass time (min) & $205 \pm 55$ \\
\hline Aortic crossclamp time (min) & $148 \pm 38$ \\
\hline Circulatory arrest time (min) & $28 \pm 12$ \\
\hline Operative time (min) & $319 \pm 78$ \\
\hline Circulatory arrest body temperature $\left({ }^{\circ} \mathrm{C}\right)$ & $25 \pm 3$ \\
\hline \multicolumn{2}{|l|}{ Complications } \\
\hline Low cardiac output syndrome & $6(11)$ \\
\hline Perioperative myocardial infarction & $1(2)$ \\
\hline Permanent neurologic deficit & $6(11)$ \\
\hline Temporary neurologic deficit & $9(16)$ \\
\hline Re-exploration for bleeding & $15(27)$ \\
\hline Sepsis & $4(7)$ \\
\hline Gastrointestinal complications & $5(9)$ \\
\hline Pulmonary complications & $19(35)$ \\
\hline Renal failure requiring dialysis & $10(18)$ \\
\hline \multicolumn{2}{|l|}{ Death } \\
\hline Intraoperative death & 0 \\
\hline Hospital mortality & $2(4)$ \\
\hline 30-d mortality & $5(9)$ \\
\hline \multicolumn{2}{|l|}{ Causes of hospital mortality } \\
\hline Intractable low cardiac output syndrome & $1(2)$ \\
\hline Major brain damage & $1(2)$ \\
\hline
\end{tabular}

Values are presented as $\mathrm{n}(\%)$, median (range) or mean \pm standard deviation. GFR, Gelatin-Resorcin-Formalin. repair: One-third of patients underwent total arch or elephant trunk replacement.

Hospital and 30-day mortality were $4 \%$ and $9 \%$, respectively, in our cohort. Permanent neurologic deficit occurred in 6 patients $(11 \%)$ (focal deficit in 4 patients, global in 1 patient, and spinal cord injury in 1 patient). When compared with the large, multicenter German Registry for Acute Aortic Dissection Type A, our David series had acceptable rates of 30-day mortality ( $9 \%$ vs $17 \%$ ) and permanent neurologic deficit (11\% vs $11 \%) .{ }^{18}$ These results demonstrate that the David procedure can be performed safely and effectively in selected ATAAD patients, even in combination with extensive aortic arch surgery.

\section{CONCLUSIONS}

The David procedure is associated with good perioperative safety and long-term efficacy in select ATAAD patients, in particular young patients and those with connective tissue disorders. The David operation is associated with decreased risk of long-term prosthetic-valve-related complications, and therefore should be considered the procedure of choice in younger, lower-risk ATAAD patients when performed by experienced surgeons.

\section{Conflict of Interest Statement}

Dr Borger's hospital receives speaker's honoraria and/or consulting fees from Edwards Lifesciences, Medtronic, Abbott, and CryoLife. All other authors reported no conflicts of interest.

The Journal policy requires editors and reviewers to disclose conflicts of interest and to decline handling or reviewing manuscripts for which they may have a conflict of interest. The editors and reviewers of this article have no conflicts of interest.

The authors thank Dr Khadzhimurad Magomedov for helping with the procurement of patient data.

\section{References}

1. Erbel R, Aboyans V, Boileau C, Bossone E, Bartolomeo RD, Eggebrecht H, et al. 2014 ESC guidelines on the diagnosis and treatment of aortic diseases: document covering acute and chronic aortic diseases of the thoracic and abdominal aorta of the adult. The Task Force for the Diagnosis and Treatment of Aortic Diseases of the European Society of Cardiology (ESC). Eur Heart J. 2014;35:2873-926.

2. Leontyev S, Légaré JF, Borger MA, Buth KJ, Funkat AK, Gerhard J, et al. Creation of a scorecard to predict in-hospital death in patients undergoing operations for acute type a aortic dissection. Ann Thorac Surg. 2016;101:1700-6.

3. Leshnower BG, Chen EP. When and how to replace the aortic root in type A aortic dissection. Ann Cardiothorac Surg. 2016;5:377-82.

4. David TE, Feindel CM. An aortic valve-sparing operation for patients with aortic incompetence and aneurysm of the ascending aorta. J Thorac Cardiovasc Surg. 1992;103:617-21.

5. Sarsam MA, Yacoub M. Remodeling of the aortic valve annulus. J Thorac Cardiovasc Surg. 1993;105:435-8.

6. Miller DC. Valve-sparing aortic root replacement in patients with the Marfan syndrome. J Thorac Cardiovasc Surg. 2003;125:773-8. 
7. Leyh RG, Schmidtke C, Sievers H-H, Yacoub MH. Opening and closing characteristics of the aortic valve after different types of valve-preserving surgery. Circulation. 1999;100:2153-60.

8. Tian D, Rahnavardi M, Yan TD. Aortic valve sparing operations in aortic root aneurysms: remodeling or reimplantation? Ann Cardiothorac Surg. 2013;2:44-52.

9. Lansac E, Di Centa I, Sleilaty G, Bouchot O, Arnaud Crozat E, Blin D, et al. An aortic ring to standardise aortic valve repair: preliminary results of a prospective multicentric cohort of 144 patients. Eur J Cardiothorac Surg. 2010;38:147-54.

10. Demers P, Miller DC. Simple modification of "T. David-V" valve-sparing aortic root replacement to create graft pseudosinuses. Ann Thorac Surg. 2004;78: 1479-81.

11. David TE. Aortic valve sparing in different aortic valve and aortic root conditions. J Am Coll Cardiol. 2016;68:654-64.

12. Oechtering TH, Hons CF, Sieren M, Hunold P, Hennemuth A, Huellebrand M, et al. Time-resolved 3-dimensional magnetic resonance phase contrast imaging (4D Flow MRI) analysis of hemodynamics in valve-sparing aortic root repair with an anatomically shaped sinus prosthesis. J Thorac Cardiovasc Surg. 2016;152:418-27.e1.

13. David TE, Feindel CM, Webb GD, Colman JM, Armstrong S, Maganti M. Longterm results of aortic valve-sparing operations for aortic root aneurysm. J Thorac Cardiovasc Surg. 2006;132:347-54.

14. de Kerchove L, Boodhwani M, Glineur D, Noirhomme P, El Khoury G. A new simple and objective method for graft sizing in valve-sparing root replacement using the reimplantation technique. Ann Thorac Surg. 2011;92:749-51.

15. Gleason TG. New graft formulation and modification of the David reimplantation technique. J Thorac Cardiovasc Surg. 2005;130:601-3.

16. De Paulis R, Chirichilli I, Scaffa R, Weltert L, Maselli D, Salica A, et al. Longterm results of the valve reimplantation technique using a graft with sinuses. $J$ Thorac Cardiovasc Surg. 2016;151:112-9.
17. Swanson M, Clark RE. Dimensions and geometric relationships of the human aortic valve as a function of pressure. Circ Res. 1974;35:871-82.

18. Conzelmann LO, Hoffmann I, Blettner M, Kallenbach K, Karck M, Dapunt O et al. Analysis of risk factors for neurological dysfunction in patients with acute aortic dissection type A: data from the German Registry for Acute Aortic Dissection Type A (GERAADA). Eur J Cardiothorac Surg. 2012;42: 557-65.

19. Leyh RG, Fischer S, Kallenbach K, Kofidis T, Pethig K, Harringer W, et al. High failure rate after valve-sparing aortic root replacement using the "remodeling technique" in acute type A aortic dissection. Circulation. 2002;106(12 Suppl 1):I229-33.

20. Subramanian S, Leontyev S, Borger MA, Trommer C, Misfeld M, Mohr FW Valve-sparing root reconstruction does not compromise survival in acute type A aortic dissection. Ann Thorac Surg. 2012;94:1230-4.

21. Mosbahi S, Stak D, Gravestock I, Burgstaller JM, Steurer J, Eckstein F, et al. A systemic review and meta-analysis: Bentall versus David procedure in acute type A aortic dissection. Eur J Cardiothorac Surg. 2019;55:201-9.

22. Leontyev S, Borger MA. David operation for type A aortic dissection: risks and rewards. Eur J Cardiothorac Surg. 2017;52:325-6.

23. Beckmann E, Martens A, Pertz J, Kaufeld T, Umminger J, Hanke JS, et al. Valvesparing David I procedure in acute aortic type A dissection: a 20-year experience with more than 100 patients. Eur J Cardiothorac Surg. 2017;52:319-24.

24. Leshnower BG, Myung RJ, McPherson L, Chen EP. Midterm results of David V valve-sparing aortic root replacement in acute type A aortic dissection. Ann Thorac Surg. 2015;99:795-800.

Key Words: aortic dissection, David, aorta and great vessels 